\title{
A REVIEW OF ANAESTHETIC TECHNIQUES FOR THE SURGICAL TREATMENT OF INTRACRANIAL ANEURYSMS
}

\author{
W. A. Doll, M.D. AND Leonard C. Jenkins, B.A., M.D., C.M., F.R.C.P (c) ${ }^{*}$
}

The NON-SURGiCAL MoRtality rate during the first six weeks following the rupture of intracranial aneurysms is approximately 45 per cent to 50 per cent.1,2,3 Of the remainder, about 20 per cent will die of recurrent haemorrhage at a later date. ${ }^{4}$ From the standpoint of reducing both the early and delayed mortality rates, as far as the good risk aneurysms are concerned, the results of surgical treatment appear to be consistently lower than the results of conservative treatment. ${ }^{3}$

The current anaesthetic management for the surgical treatment of these patients is centered around four main techniques (Table I).

TABLE I

ANAESTHETIC TEChNique FOR

SURGical TREatMent of

INTRACRANIAL ANEURYSM

(1) Hypothermia with normotension

(2) Normothermia with hypotension

(3) Hypothermia with hypotension

(4) Normothermia with normotension

For the purposes of this presentation, hypothermia will be defined as an oesophageal temperature of $28^{\circ}$ to $30^{\circ} \mathrm{c}$. Almost all the patients in the series had inadvertent temperature decreases of from $1^{\circ}$ to $3^{\circ} \mathrm{C}$, but were nevertheless regarded as being normothermic. Hypotension is defined as a systolic arterial blood pressure of $70 \mathrm{~mm} \mathrm{Hg}$ or lower maintained at that level for a period of not less than fifteen minutes.

\section{Material}

This series consists of 79 patients, studied retrospectively, who had clipping of intracranial aneurysms performed at the Vancouver General Hospital between 1 January 1966 and 31 December 1968. One patient had a repeat clipping of the same aneurysm, and five patients each had a second aneurysm clipped. The total number of procedures to be reported on is 85 .

The types of premedication combinations that were employed are shown on the premedication grid (Table II). Atropine alone or in combination with promethazine, and hyoscine alone or in combination with meperidine or promethazine were used most frequently.

Induction was with thiopentone in all but two patients. Relaxation for intu-

-Department of Anaesthesia, University of British Columbia and The Vancouver General Hospital. 


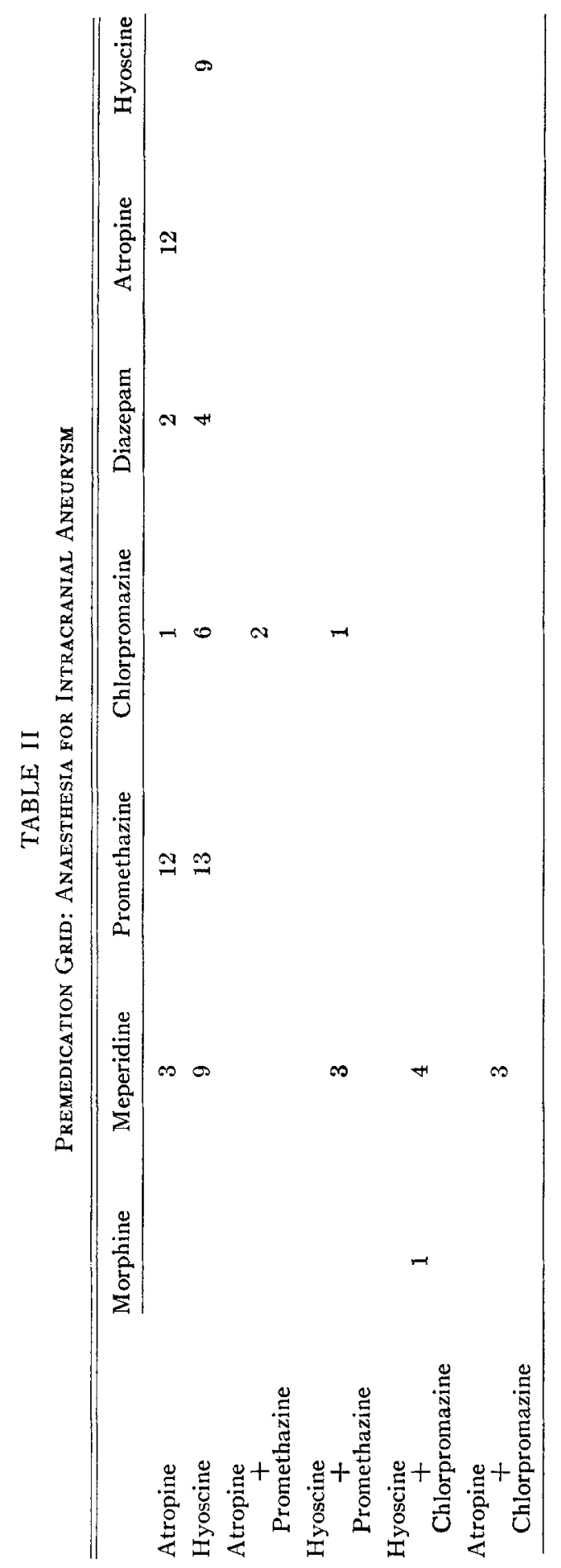


bation was achieved with succinylcholine in 62 patients, d-tubocurare in 21 patients, and with gallamine in the remaining two. Additional relaxation during surgery was accomplished with additional d-tubocurare in 58 patients and with gallamine in 14. Respirations were spontaneous throughout the procedure in seven patients, controlled with an Engstrom respirator in 6 patients, and with a Bird respirator in 72 .

Nitrous oxide 3 liters to oxygen 2 liters was the most frequently employed basic gas mixture, and this was administered by a semi-closed carbon dioxide absorption circuit. Halothane was the maintenance agent in 70 patients, methoxyflurane in 12, "lytic cocktail" solution containing meperidine 0.04 per cent, chlorpromazine 0.01 per cent, promethazine 0.01 per cent, in two patients and alphaprodine in one patient. Supplementary intravenous narcotic during the procedure was administered to eleven patients using meperidine and to sixteen patients using alphaprodine. Mannitol in a dosage range of from 1 to $1.5 \mathrm{gms}$ per kilo was administered to all but five patients. Dexamethasone was given to practically all the patients, either before, during, or immediately after surgery.

Hypothermia was achieved by circulating surface cooling blanket (Thermorite), along with ice packs applied to superficial artery sites, such as the neck, axilla, and inguinal regions. It was performed in a total of 45 patients. Active rewarming was instituted as soon as the aneurysm was clipped, and continued until the temperature had risen to $32.5^{\circ} \mathrm{c}$, at which time the patient was permitted to leave the operating theatre.

Hypotension was produced either by increasing the concentration of halothane, if this was the agent employed, or by the addition of trimethaphan in a 0.1 per cent solution. The latter agent was used in 32 patients.

Additional monitoring included continuous EKG and Wright respirometry in all cases; blood gas determinations $\mathrm{Po}_{2}, \mathrm{Pco}_{2}, \mathrm{pH}$, and $\mathrm{HCO}_{3}$ ), and central venous pressure recordings were performed in about 30 per cent of the patients. Facilities for recording continuous radial artery blood pressure directly, became available only toward the end of the series.

Continuous oxygen was administered during the transport of the patient to the anaesthetic recovery room, where a moist-air, oxygen enriched mixture ( 40 per cent or 60 per cent) was delivered for periods ranging from 12 to 48 hours postoperatively.

\section{RESULTS}

The locations of the aneurysms and the mortality rate are shown in Table III. There was an overall mortality rate of 23.5 per cent, which was almost identical with that reported in an earlier series from this hospital. ${ }^{5}$ The average interval between surgery and death was sixteen days, the median interval was seven days. Two patients died on the 46th and 120th postoperative days, and a third patient died on the 11th postoperative day as a result of an acute intra-abdominal condition. Exclusion of these three patients would result in a mortality rate of 20 per cent, which is comparable to the 18.4 per cent reported by Marshall $e t a .^{6}$

Table IV gives the Botterell Classification ${ }^{7}$ of the aneurysms, and the associated mortality occurring in each grade. In the good risk cases, i.e. the Grade I and Grade II patients combined, the mortality rate was 13.6 per cent. 
TABLE 111

Site of Aneurysm and Associated Mortality

\begin{tabular}{|c|c|c|c|}
\hline Site of aneurysm & No, of cases & Survivals & $\begin{array}{l}\text { Mortality } \\
\text { rate (per cent) }\end{array}$ \\
\hline \multicolumn{4}{|l|}{ Ant. communicating } \\
\hline and ant. cerebral & 25 & 17 & 32 \\
\hline $\begin{array}{l}\text { Internal carotid } \\
\text { Middle cerebral }\end{array}$ & 34 & 26 & 23.5 \\
\hline Middle cerebral & 22 & 18 & 18 \\
\hline Miscellaneous* & 4 & 4 & 0 \\
\hline
\end{tabular}

*2 basilar artery and 2 posterior cerebral artery aneurysms.

TABLE IV

Mortality of Intracranial Aneurysms According to Grade

\begin{tabular}{cccc}
\hline Grade & No. of cases & Survivals & $\begin{array}{c}\text { Mortality } \\
\text { rate } \\
\text { (per cent) }\end{array}$ \\
\hline I & 40 & 38 & 5 \\
II & 26 & 19 & 26.9 \\
II & 18 & 8 & 45.5 \\
\hline
\end{tabular}

TABLE V (GROUP A)

Hypothermia with Normotension (Deaths shown in Brackets) (TOTAL 31)

\begin{tabular}{rcccc}
\hline Grade & $\begin{array}{l}\text { Anterior } \\
\text { cerebral }\end{array}$ & $\begin{array}{l}\text { Internal } \\
\text { carotid }\end{array}$ & $\begin{array}{c}\text { Middle } \\
\text { cerebral }\end{array}$ & Miscellaneous \\
\hline I & 1 & 6 & 5 & 0 \\
II & $4(2)$ & 4 & $2(1)$ & 1 \\
III & $2(2)$ & $4(3)$ & 1 & 1 \\
\hline
\end{tabular}

TABLE VI (GROUP B)

Normothermta with Hypotension (Deaths show in Brackets) (TOTAL 30)

\begin{tabular}{ccccc}
\hline Grade & $\begin{array}{c}\text { Anterior } \\
\text { cerebral }\end{array}$ & $\begin{array}{c}\text { Internal } \\
\text { carotid }\end{array}$ & $\begin{array}{c}\text { Middle } \\
\text { cerebral }\end{array}$ & Miscellaneous \\
\hline I & $7(2)$ & 7 & 3 & 1 \\
II & $2(1)$ & $2(1)$ & 1 & 1 \\
III & 1 & $3(2)$ & 2 & 0 \\
\hline
\end{tabular}

The locations and grades of the 31 aneurysms (group A) that were operated on with hypothermia and normotension are shown in Table V. For the entire group the mortality was 25.8 per cent, but for the good risk patients (Grades I and II) it was 13 per cent. The average number of days from surgery to discharge was 29 .

Those patients (group B) operated on with normothermia and hypotension totalled 30 in number (Table VI). The mortality for the whole group was 20 per cent, and 16.6 per cent for the good risks (Grades I and II). The average number of days in hospital following surgery was 35 . 
TABLE VII (GROUP C)

Hypothermia WITH HyPOTENSION (DEATHS SHOWN IN BRACKETS) (TOTAL 14)

\begin{tabular}{rccc}
\hline \hline Grade & $\begin{array}{l}\text { Anterior } \\
\text { cerebral }\end{array}$ & $\begin{array}{l}\text { Internal } \\
\text { carotid }\end{array}$ & $\begin{array}{l}\text { Middle } \\
\text { cerebral }\end{array}$ \\
\hline I & 4 & 1 & 2 \\
II & 2 & 1 & $2(1)$ \\
III & $1(1)$ & $1(1)$ & 0 \\
\hline
\end{tabular}

TABLE VIII (GROUP D)

NoRMOTHERMIA WITH NORMOTENSION (DEaTHS SHOWN IN BRACKets) (TOTaL 10)

\begin{tabular}{rccc}
\hline \hline Grade & $\begin{array}{c}\text { Anterior } \\
\text { cerebral }\end{array}$ & $\begin{array}{c}\text { Internal } \\
\text { carotid }\end{array}$ & $\begin{array}{c}\text { Middle } \\
\text { cerebral }\end{array}$ \\
\hline I & 0 & 2 & 1 \\
II & 1 & $2(1)$ & 1 \\
III & 0 & 1 & $1(1)$ \\
IV & 0 & 0 & $1(1)$ \\
\hline
\end{tabular}

TABLE IX

Incidence of Temporary Proximal Occlusion, Operative Rupture, Mortality Rates, and LeNGTH of Hospitalization

\begin{tabular}{cccccc}
\hline \hline & $\begin{array}{c}\text { Incidence } \\
\text { of } \\
\text { temporary } \\
\text { proximal } \\
\text { occlusion } \\
\text { (per cent) }\end{array}$ & $\begin{array}{c}\text { Incidence } \\
\text { of } \\
\text { rupture } \\
\text { (per cent) }\end{array}$ & $\begin{array}{c}\text { Good risk } \\
\text { (grades \& \& II) } \\
\text { mortality } \\
\text { (per cent) }\end{array}$ & $\begin{array}{c}\text { Total } \\
\text { mortality } \\
\text { rate } \\
\text { (per cent) }\end{array}$ & $\begin{array}{c}\text { Days } \\
\text { in hospital } \\
\text { post-surgical }\end{array}$ \\
\hline Group & 84 & 29 & 13 & 25.8 & 29 \\
B & 6.6 & 37 & 16.6 & 20 & 35 \\
C & 50 & 21 & 8.3 & 21.5 & 32 \\
D & 20 & 30 & 14 & 30 & 29 \\
\hline
\end{tabular}

Table VII shows the 14 patients (group c) managed with both hypothermia and hypotension. Here the total mortality was 21.5 per cent; the good risk (Grades I and II) mortality was only 8.3 per cent. The average post-operative hospital stay was 32 days.

Only 10 patients (group D) had surgery performed at normal temperature and normal blood pressure (Table VIII). The total mortality was 30 per cent and 14 per cent in the good risk group. The average postoperative hospital stay was 29 days. This group is probably a somewhat favoured group in that it was seldom necessary to induce hypotension, presumably because of the lack of technical difficulty in exposing and clipping the aneurysm. If difficulty had been encountered, a request for a drop in blood pressure would have been made by the surgeon, which then would automatically have placed such a patient in group B (normothermia with hypotension).

Table IX shows the incidence of temporary proximal vessel occlusion, the incidence of operative aneurysm rupture, the various mortality rates, and the 
periods of postoperative hospitalization associated with the four groups of patients. Proximal vessel occlusion was performed in a total of 33 patients, who were done with hypothermia, compared to only four patients done with normothermia. The average length of temporary proximal vessel occlusion in the hypothermia survivors was 14.3 minutes, compared to 12 minutes in the nonsurvivors. In the patients done at normal temperature, these times were 9 minutes for the survivors and 5.5 minutes for the non-survivors.

\section{Discussion}

The mortality rate for all the aneurysms managed with hypothermia was 24.4 per cent, compared to 22.4 per cent of those managed with normothermia. This is in keeping with Hamby's experience that hypothermia did not improve the survival rates of patients operated upon for bleeding intracranial aneurysms. ${ }^{8}$ However, the same could not be said for the good risk patients, since the mortality rate for both hypothermic groups ( A \& C) was 11.4 per cent, as opposed to 16.1 per cent for both normothermic groups ( $\mathrm{B} \& \mathrm{D}$ ). The lowest good risk mortality rate ( 8.3 per cent) was in the patients managed with the hypothermia and hypotension combination (group c). Since there were only 14 patients in this group, it is probably not valid to conclude that this technique was actually superior. It may bear repeating that this group also had the lowest incidence of aneurysm rupture during surgery.

Temporary vessel occlusion when performed was on single vessels in all but three patients. Since it was performed in 73.3 per cent of the hypothermia patients, but in only 10 per cent of the normothermia patients, a meaningful comparison between the two groups could not be made. The fact that in both groups the average length of occlusion was longer in the survivors than in the non-survivors probably indicates the ineffectiveness of interrupting the circulation completely with this type of occlusion.

Whether or not mortality should be regarded as the sole index in comparing the relative merits of the anaesthetic techniques employed may be open to question. However, in one sense it does provide an absolute and objective quantitative end-point. The incidence and extent of permanent neurological deficits amongst the survivors is obviously not reflected by the mortality rate. It was therefore felt that the period of convalescence in hospital following surgery might serve as a possible criterion of the relative morbidity when comparing the various groups of patients. One would expect that patients with the more serious neurological deficits would remain in hospital for a longer period of time. Taking the group as a whole, it was found that very little difference existed in this respect. The patients in group a (hypothermia and normotension) remained for 29 days, those in group $\mathbf{B}$ (normothermia and hypotension) remained 35 days, group $\mathrm{c}$ (hypothermia and hypotension) remained 32 days, while those in group $\mathrm{D}$ (normothermia and normotension) remained for 29 days. If this is indeed an acceptable means of comparing morbidity, then one would have to conclude that it is very evenly distributed throughout the four groups studied. 
In addition to rendering the patient insensitive to the painful stimuli of surgery, anaesthesia should preferably also facilitate the exposure of the vessels at the base of the brain and aid in the prevention and control of bleeding from the aneurysm itself while it is being dissected free and clipped. Exposure may be regarded as being directly related to the actual bulk of the brain, and this can be quite markedly reduced by the action of the osmotic dehydrating substances such as mannitol., ${ }^{9,10}$ Despite the use of this agent in 80 per cent of the patients, the surgeons frequently complained about the lack of slackness of the brain, and it wasn't until the surgery had progressed to a stage where cerebrospinal fluid could be suctioned from the basal cysterns that exposure no longer appeared to be of any major concern. This is a well recognized, previously reported observation. ${ }^{11}$

Another commonly practiced method of reducing brain size is hyperventilation, ${ }^{12}$ but this is likely to produce a three- to fourfold increase in cerebrovascular resistance ${ }^{13}$ and to result in a decreased cerebral perfusion. ${ }^{14}$ The avoidance of hypocarbia has been suggested as the most important single factor in assuring adequate cerebral perfusion during hypotension. ${ }^{17}$ Since hypothermia has also been shown to produce a marked increase in cerebrovascular resistance, ${ }^{11,18}$ it would appear advisable to adjust ventilation to maintain $\mathrm{PCO}_{2}$ as close to normal as possible, especially when hypotension is combined with hypothermia. Cerebral venous drainage can usually be adequately provided for by means of a slight ${ }^{10}$ reverse Trendelenburg position, and a clear unobstructed endotracheal airway. Quiet, relaxed, spontaneous respirations may suffice, but if it becomes necessary to ventilate the patient actively, then the administration of a long-acting muscle relaxant may often be conducive to lowering the central and epidural venous pressures secondary to relaxation of the abdominal muscles. Large negative expiratory pressures during controlled respiration should rarely be necessary.

The decision as to the technique to be employed in any given instance was usually made by the neurosurgeon in consultation with the anaesthetist. No particular trend or preponderance of any one technique in relation to aneurysm site or grade could be established, but there appeared to be a preference for hypothermia when more than the usual amount of technical difficulty in dealing with the aneurysm was anticipated. Hypotension was instituted as a therapeutic measure in nearly all the instances of operative aneurysm rupture, and helped appreciably in bringing the situation under control. Hypothermia induced prophylactically as well, both with and without hypothermia, particularly as the series progressed. In view of the slightly better survival rate in the good risk cases, when hypothermia was employed in combination with hypotension, it would appear feasible to persist with this technique for the time being, until an analysis of a larger series is possible.

\section{Summary}

The current methods of anaesthetic management of patients for the surgical treatment of ruptured intracranial aneurysms have been discussed. These may be classified in four groups, which are: 
(1) hypothermia with normotension

(2) normothermia with hypotension

(3) hypothermia with hypotension

(4) normothermia with normotension

The anaesthetic records and hospital charts of 85 cases have been reviewed and employed as a basis for comparison and discussion. These patients were treated at the Vancouver General Hospital between 1 January 1966 and 31 December 1968. A brief outline of the anaesthetic techniques and agents employed is presented. The cases are analyzed as to:

(1) mortality

(2) surgical ease of dealing successfully with the aneurysm

(3) postoperative morbidity as reflected by the length of hospital confinement. Taking into consideration the Grade I and Grade II patients only (the good risk cases) the mortality rate was 11.4 per cent with hypothermia, and 16.1 per cent with normothermia. The lowest good-risk mortality was found in the group of patients managed with the hypothermia and hypotension combination. There was very little difference in the average number of days that the patients remained in hospital following surgery, regardless of the anaesthetic technique employed.

\section{RÉSUMÉ}

Il s'agit dans ce travail des techniques courantes d'anesthésie pour le traitement chirurgical d'anévrysmes intracraniens rupturés. On peut les classifier en quatre groupes, comme suit:

(1) hypothermie avec tension normale

(2) température normale avec hypotension

(3) hypothermie avec hypotension

(4) température normale avec tension normale.

On a revisé et utilisé comme base de comparaison et de discussion les dossiers de l'hôpital et ceux de l'anesthésie de 85 cas. Ces malades ont été traités au "Vancouver General Hospital" entre le ler janvier 1966 et le 31 décembre 1968. On présente un bref aperçu des techniques et des agents anesthésiques utilisés. Les cas sont analysés par rapport à:

(1) la mortalité

(2) la facilité chirurgicale d'atteindre l'anévrysme avec succès

(3) la morbidité post-opératoire d'après la durée d'hospitalisation.

Si l'on considère les cas à l'état physique I et II (les bons risques), le taux de mortalité a été de 11.4 pour cent avec hypothermie et de 16.1 pour cent sans hypothermie. Le taux de mortalité le plus bas chez les bons risques s'est trouvé dans le groupe de malades soumis à l'association hypothermie et hypotension. La technique anesthésique utilisée a eu peu d'influence sur la durée d'hospitalisation post-opératoire.

\section{REFERENCES}

1. Gurdjian, E. S. \& Thomas, L. M. Operative Neurosurgery. Baltimore: The Williams \& Wilkins Co. p. 316 (1970).

2. Davis, L. \& Davis, R. A. Principles of Neurological Surgery. Philadelphia: W. B. Saunders Co. p. 189 (1963). 
3. Lougheed, W. M. \& Marshall, B. The Place of Hypothermia in the Treatment of Intracranial Aneurysms. Prog. Neurol. Surg. 3: 115-148 (1969).

4. McKissock, W. \& WALSH, L. Subarachnoid Haemorrhage Due to Intracranial Aneurysms. Brit. M. J. 2: 559 (1956).

5. Moyes, P. D. Management and Surgical Treatment of Ruptured Intracranial Aneurysms. Canad. M. A. J. 94: 1 (1966).

6. Marshall, B. M.; Lougheed, W. M.; \& Gordon, R. A. Evaluation of the Effect of Anaesthetic Techniques on Survival After Intracranial Surgery for Ruptured Aneurysms. Canad. Anaesth. Soc. J. 15: 3 ( 1968).

7. Bottereli, E. H.; Lougheed, W. M.; Scott, J. W.; \& Vandewater, S. L. Hypothermia and Interruption of Carotid, or Carotid and Vertebral Circulation, in the Surgical Management of Intracranial Aneurysms. J. Neurosurg. 13: 1 (1956).

8. Hemsy, W. B. Intracranial Surgery for Aneurysm. Effect of Hypothermia Upon Survival. J. Neurosurg. 20: 41 (1963).

9. Wise, B. L. \& Charter, N. Use of Hypertonic Mannitol Solution in Decreasing Brain Mass and Lowering Cerebrospinal Fluid Pressure. J. Neurosurg. 19: 1038-1043 (1962).

10. Shenkin, H. A.; Gluboff, B.; \& Haft, H. The Use of Mannitol for the Reduction of Intracranial Pressure in Intracranial Surgery. J. Neurosurg. 19: 897 (1962).

11. Rosomoff, H. L. \& Holoday, D. A. Cerebral Blood Flow and Cerebral Oxygen Consumption During Hypothermia. Am. J. Physiol. 179: 85 (1954).

12. Jenkiss, L. C. General Anaesthesia and the Central Nervous System. Baltimore: The Williams and Wilkins Co. Part III, Chap. 5 (1969).

13. Pience, E. C., Jr.; Lambersten, C. J.; Deutsch, S.; Chase, P. E.; Linde, H. W.; Dripps, R. D.; \& Price, H. L. Cerebral Circulation and Metabolism During Thiopental Anaesthesia and Hyperventilation in Man. J. Clin. Invest. 41: 1664 (1962).

14. Robinson, J. S. \& Gray, T. C. Observations on the Cerebral Effects of Passive Hyperventilation. Brit. M. J. 2: 240 (1963).

15. Allcock, J. M. \& Drake, C. G. Ruptured Intracranial Aneurysms - The Role of Arterial Spasm. J. Neurosurg. 27: 21 (1965).

16. Krueger, T. P.; Rockoff, S. D.; Thomas, L. J.; \& Ommaya, A. K. The Effect of Changes of End Expiratory Carbon Dioxide Tension on the Normal Cerebral Angiogram. Am. J. Roentgenol. 90: 506-511 (1963).

17. LARSON, A. G. Deliberate Hypotension. Anesthesiology 25: 682-706 (1964).

18. Rosomoff, H. L. Hypothermia and the Central Nervous System. Proc. Nat. Acad. Sci. (Wash.) 451: 253 (1956). 